\title{
How do teachers' perceptions of climate change vary in terms of importance, causes, impacts and mitigation? A comparative study in Bangladesh
}

\author{
Mohammed Thanvir Ahmed Chowdhury ${ }^{1} \cdot$ Khandaker Jafor Ahmed $^{2}$. \\ Mufti Nadimul Quamar Ahmed ${ }^{1}$. Shah Md. Atiqul Haq ${ }^{3}$ (D)
}

Received: 8 December 2020 / Accepted: 22 June 2021 / Published online: 21 July 2021

(c) The Author(s), under exclusive licence to Springer Nature Switzerland AG 2021

\begin{abstract}
Since climate change education is an integral element in the increasingly urgent global approach to solving the problem of climate change, understanding perceptions of climate change among teachers in different academic institutions could play a significant role in how and to what extent institutions address the need to educate learners on this subject, specifically, and participate in other climate change mitigation strategies, in general. This study, therefore, examines teachers' perceptions of climate change regarding its significance, causes, consequences, and mitigation, through analysis of a self-administered structured questionnaire completed by 95 teachers from public and private educational institutions in the city of Sylhet in Bangladesh. Results from descriptive and inferential statistical analysis show that public and private school teachers have an understanding of climate change regarding its significance, causes, consequences, and mitigation. The results also reveal that the sociodemographic characteristics of teachers, as well as academic-related factors, influence their perceptions of climate change. This research concludes that teachers in public institutions have a greater awareness and understanding of climate change than those working in private schools. The research findings have broader implications for further research and policy recommendations and, in particular, draw the attention of the Departments of Education and Disaster Management in Bangladesh or in countries with similar contexts to introduce environmental and disaster education and training opportunities for teachers.
\end{abstract}

Keywords Perceptions of climate change - Climate change education - Private schools and colleges $\cdot$ Public schools and colleges $\cdot$ Teachers $\cdot$ Bangladesh

Shah Md. Atiqul Haq

shahatiq-soc@sust.edu; shahatiq1@yahoo.com

Extended author information available on the last page of the article 


\section{Background and introduction}

One of the biggest challenges of the current century is climate change (Choon et al. 2019). Over the past two decades, the science behind and the social and economic impacts of global climate change has been the subject of national and international research (Rahman and Lateh 2017; Sarkar et al. 2012). While there is a broad debate about how much of a role human activities play in accelerating or slowing climate change, people are urged to understand the causes of climate change and be aware of the profound changes they will be expected to make in lifestyle, consumption, and production (Giddens 2009). Accordingly, researchers are paying increasing attention to human attitudes, beliefs and perceptions regarding global climate change (Sarkar et al. 2012).

It is clear that human knowledge, perceptions, and awareness have an impact on behavioural strategies developed to address climate change (Scannell and Gifford 2013). Specifically, mitigation behaviour that aims to rapidly reduce the impacts of climate change is influenced by the perceived risks and impacts of climate change at the individual or group level. As societies and governments plan for climate change adaptation and develop sustainable policies, it is critical that knowledge about climate change and its social and economic impacts be shared and understood (Crona et al. 2013; Wolf and Moser 2011). In this regard, education at different educational institutions about the importance, causes and consequences of climate change can play a vital role in long-term climate change adaptation and mitigation measures (Bangay and Blum 2010).

It is persuasively argued that human activities are the leading cause of climate change, and humans are primarily responsible for the increasing emissions of greenhouse gases (IPCC 2014). Research has shown that human-driven deforestation, industrialisation, population growth, excessive carbon emissions, rapid urbanisation and lifestyle changes are associated with climate change (Kabir et al. 2016). It is important to note related findings that demonstrate that vulnerable populations in different climate-sensitive areas perceive climate change as resulting from supernatural forces or God (Debela et al. 2015), disobedience to God's order (Ahmed and Haq 2019), and human activities (Shi et al. 2016). Common perceptions and beliefs like these are not consistent with scientific consensus because climate change is an inherently tricky concept to understand, and beliefs arise from frequent misunderstandings (Shealy et al. 2019).

The impacts of climate change on different sectors, including but not limited to cultural, economic, environmental and health, occur on a personal and global scale. To mitigate these impacts, people must change their beliefs and activities. One of the best ways to change perceptions and beliefs is through education, particularly science education (Herman et al. 2017). Education is also a powerful part of the religions and cultures that shape people's perspectives. Therefore, education has a significant impact on how people might perceive climate change (Nakayama 2019). Climate change education is inextricably linked to climate crisis management. School-based climate and disaster education programmes can help build the knowledge, skills and attitudes people need to prepare for and cope 
with disasters and help students and the community build resilience to these as well as natural hazards (Habiba et al. 2013; Selby and Kagawa 2012).

Therefore, environmental educators need to be engaged in building climate change education in schools (Ho and Seow 2017). Morgado et al. (2017) emphasised that higher education institutions also need to get involved and seek regional solutions to this global problem. Higher education institutions must adapt new curricula, teaching strategies and assessment methods to change student behaviours in the face of climate change and its impact on the environment. However, it is critical to first examine cross-cultural perceptions of climate change among these teachers and institutions to gain a comprehensive understanding of continuing education and communication policies. Many studies have addressed how people misunderstand climate change, with respect to, for example, the effects of global warming or the link between ozone depletion and climate change. Many of these studies have explicitly suggested addressing this lack of knowledge among school teachers in particular, on topics related to the impacts, causes and mitigation of climate change (Ho and Seow 2017).

This study aims to understand teachers' perceptions of climate change in private and public schools in Bangladesh. It builds upon and extends existing studies of perceptions of climate change in terms of causes, consequences and mitigation in developing countries where the risk of climate-related extreme events is high (Ullah et al. 2019). Bangladesh, despite contributing very little to global greenhouse gas emissions, is often cited as one of the countries most threatened by climate change, (Anik and Khan 2012). Its geography and the widespread poverty of its citizens makes Bangladesh significantly vulnerable to climate change and extremes (The Asia Foundation 2012). In Bangladesh, studies of people's perceptions of climate change have been conducted among high school students (Rahman et al. 2014), among indigenous peoples (Ahmed and Haq 2019; Huda 2013; Kabir et al. 2016) and at the household level of those living in flood-affected areas (Haq and Ahmed 2017). To the best of our knowledge, there is a gap in adequate published research on teachers' perceptions of climate change in Bangladesh that we seek to fill. Our study also contributes to the body of research into the extent to which perceptions are related to past experiences of climate change impacts, knowledge about climate change and individual personality traits (Bryan 2003; Stooksberry et al. 2009), and the beliefs that shape thinking and actions, particularly in responding to the impacts of climate change (Rimm-Kaufman et al. 2006).

It is critical to understand teachers' perceptions of climate change as these perceptions, shared through regular interactions, will affect their students' understanding of climate change and related issues. It is logical to expect that teachers teaching courses related to the environment/climate change/disasters will transfer their knowledge, beliefs and practices to their students.

The structure of the article is as follows. The next section introduces readers to the formal education system in Bangladesh. This is followed by a discussion of perceptions of climate change and how these are being addressed internationally. After this, we describe the target population, data collection procedures and analysis techniques of our study. We then present detailed results of our survey. We wrap up the article with a concluding discussion and suggestions for further research. 


\section{The education system in Bangladesh}

The current formal education system in Bangladesh is broadly divided into two major types: general education and religious education. Our research focuses on teachers working in general education, which is divided into three main levels in Bangladesh: primary, secondary, and tertiary/higher education. Primary education provides basic schooling over a period of 5 years (grades 1-5), and is followed by 7 years of secondary education (grades 6-12). According to the Directorate of Primary Education (DPE) (2016), basic or primary education is provided to approximately 19 million children in Bangladesh at 126,615 primary schools. All students attending elementary school at the end of fifth grade in Bangladesh are required to take a national examination administered by the Ministry of Primary and Secondary Education called the Primary Education Completion Examination (PECE) or Primary School Certificate (PSC). Secondary education is divided into three successive stages: 3 years for junior secondary (grades 6-8), 2 years for secondary (grades 9-10), and 2 years for higher secondary (grades 11-12). Students who are at the end of eighth grade take a public examination, the Junior School Certificate (JSC), which is followed by the Secondary School Certificate (also called SSC or Matriculation Examination, hereafter referred to as SSC) and the Higher Secondary Certificate (also called HSC or Intermediate, hereafter referred to as HSC) at the end of the tenth and twelfth grades, respectively. It is important to note that curriculum streaming, in which students can determine the direction of their future study by choosing either general and technical-vocational education, starts at grade 9. Our study focuses on teachers working in general education. Within general education, students seeking to gain their SSC and HSC must choose to pursue one of three disciplines: Humanities, Business, and Science. Tertiary or higher education offers several specialisations, such as higher education in general, technical, technological and medical fields, which require a further 5 to 6 years of schooling to obtain a master's degree (Chowdhury and Sarkar 2018).

These three levels of education are delivered through three distinct streams. The main stream is delivered in Bengali and is characterised as a secular education system that dates back to before the country's independence. The second stream is Madrasa education, a religious education system, and the third stream is English-medium education. All three educational systems run in parallel and prepare students for higher education at the tertiary level. However, given differences in language and culture, there is a lack of uniformity across the educational institutions and the curricula offered in Bangladesh, despite a constitutional mandate (Article 17) to ensure a uniform, mass-oriented and universal education system (BANBEIS 2011).

Schools are also divided into two types, according to their management and ownership: government, or public, schools and non-government, or private, schools. Public schools are financed and managed by the state, and private schools are privately owned and funded through tuition fees to maintain their infrastructure development and other maintenance costs (BANBEIS 2006). The syllabus 
and the course contents in both private and public schools are likely to be the same; however, higher standards are maintained in private schools (Hossain et al. 2019). Teacher autonomy varies by the type of institution. Teachers in public schools enjoy greater autonomy in teaching and running their courses. Teachers in public schools operate less under the supervision of higher-level authorities and have greater flexibility in work and teaching schedules. In private schools, on the other hand, teachers are under the strict supervision of higher authorities to ensure that their performance and work character are more structured and disciplined. In private schools, teachers have less autonomy over what and how they teach and are only concerned with delivering the course content and making lessons enjoyable for students (Asadullah 2009).

In general, private schools are more attractive to Bangladeshi parents. This is a common phenomenon prevailing in South Asian countries such as Bangladesh, India, and Pakistan (Asadullah 2009). The infrastructure of public schools can not compare to that of modernised private schools; at private schools, teachers are more committed to bringing out the best results from their students. Private schools develop teaching practices, conduct staff training and create educational materials to increase their competitiveness, as Bangladeshi parents choose schools for their children influenced by the popularity of the school and the perceived quality of its education (Suppramaniam 2019). Generally speaking in Bangladesh, children from well-off families and with highly educated parents are more likely to enrol in private schools than in public or other types of educational institution (Cameron 2011). This could be due to the better results private students achieve in exams. Students in private schools in India and Pakistan were also found to perform better in exams than their public school counterparts (Aslam 2007; Khan and Kiefer 2007; Muralidharan and Kremer 2008).

As we seek to understand the perceptions of climate change and its impacts among teachers working within general education in Bangladesh, it is essential to find out if the perceptions of public and private school teachers differ, and to determine how these perceptions are influenced by sociodemographic characteristics.

\section{Perceptions of climate change: importance, causes, impacts and mitigation}

There is a consensus that not only is climate change happening, but that it is also one of the most sensitive issues that must be addressed worldwide. Several studies discussed below have explained the importance of environmental education to the pursuit of environmental sustainability and climate change awareness. Although many colleges and universities have found students are interested in following new environmental and (or) climate change curricula, there are still barriers to change within educational institutions (Hess and Collins 2017) arising where public opinion and media leaders have developed and spread misconceptions about environmental issues. In this context, climate education in educational institutions is particularly important, as it can serve as an essential source of information to counter such misconceptions and ultimately contribute to the mitigation of climate change. Any 
change in teachers' thoughts about climate change can bring about a predictable change in students; teachers who perceive that climate change is a serious problem can lead students to perceive the same (Stevenson et al. 2016). On the other hand, if prevailing beliefs among local and national policymakers understate environmental problems, higher education is likely to have less impact on student engagement regarding climate change (Hess and Collins 2017).

Many international organisations such as the National Aeronautics and Space Administration (NASA), the National Science Foundation (NSF), and the National Oceanic and Atmospheric Administration (NOAA) have focussed on raising public awareness of the threats associated with global climate change by providing grants each year. These organisations help develop the education system by providing educational materials for elementary and secondary school teachers. These efforts are guided by the belief that teachers should provide scientific information about climate change to students in a logical way. This is especially true because climate change education in schools and colleges can actually be detrimental if teachers are not well- and scientifically informed about climate change. Littrell et al. (2020) point out that it is important for teachers and students to learn about the causes, consequences and mitigation of climate change because climate change continues to affect communities around the world, even while the process of climate change is slow (Choon et al. 2019). It is argued that greenhouse gas emissions have reached levels unprecedented since pre-industrial times (Hussain et al. 2020; Shaffril et al. 2018). Various human activities, including but not limited to agriculture, industrialisation, deforestation, uninterrupted use of non-renewable resources, transportation, air pollution and domestic energy use, have been identified as being responsible for increased global warming and climate change (Punter et al. 2011; Ding et al. 2011).

Climate change generates both short- and long-term consequences (Shaffril et al. 2018). The consequences of climate change include a greater frequency of famines and changes in rainfall patterns (Gorst et al. 2018), water levels and weather (Meilinda et al. 2017). Consequences like these, in turn, have implications for the agricultural sectors and economies of countries such as Pakistan (Hussain et al. 2020) and Bangladesh (Akanda and Howlader 2015). A study by Punter et al. (2011) among high school students in Spain shows that participants were able to identify various impacts of climate change such as losses of agricultural production (see details of Akter and Bennett 2011; The Asia Foundation 2012; Ahmed and Haq 2019), more frequent flooding and temperature increases, as well as health problems, water problems and even emotional disturbances (see details of Meilinda et al. 2017). Prokopy et al. (2015) found in their research that Scottish farmers are concerned about climate change threats and believe more significant productivity losses are possible due to climate change impacts. Meilinda et al. (2017) show that most science teachers and educators in South Sumatra believe that climate change and global warming affect their social lives.

Mitigation and adaptation are two widely used coping strategies employed at an individual level to address the negative impacts of climate change worldwide (Hussain et al. 2019; Masud et al. 2017). For governments and communities to effectively promote and implement programmes to support these strategies, people need to recognise that human activities cause climate change (Reser and Swim 2011), 
and that humans have the capacity to mitigate the impacts of climate change (Alves et al. 2018; Morgado et al. 2017). Studies have shown that people believe technology can enable humans to survive and adapt to global warming and climate change (Porter et al. 2012; Shepardson et al. 2012). Thanks to technological innovations, for example, it is increasingly possible and easy to make behavioural changes related to climate change, such as reducing energy consumption, using less gasoline and using renewable energy sources (Semenza et al. 2008). A lack of public support, the high costs of adaptation measures and a lack of adequate climate change financing are the main barriers to climate change adaptation (Akhtar et al. 2019). Other barriers include: a lack of knowledge about the causes, consequences and potential solutions of climate change; a distrust of information sources; and expectations that governments and industry must take the initiative to make changes, in the first instance (Ahmed and Haq 2019; Lorenzoni et al. 2007).

\section{Methods and materials}

\section{A brief introduction to Sylhet}

Sylhet is a northeastern district of Bangladesh, bounded in the north and east by India. The Surma-Kushiyara floodplain determines the physiography of this region (BBS 2021). Flood is the most common climate-induced disaster of many low-lying parts of the district, and this district is highly susceptible to earthquakes (Barua et al. 2016). Weather station data from 1981 to 2010 showed that the monthly average rainfall was $344 \mathrm{~mm}$, and that the minimum and maximum temperatures were 19.6 and $30.0{ }^{\circ} \mathrm{C}$, respectively (BBS 2021). In 2016, the rural and urban literacy rates of residents 7 years and over in the Sylhet division ${ }^{1}$ were $59.1 \%$ and $67 \%$, respectively (BBS 2019). In 2010, the number of government-operated primary schools was the lowest of those in the country, at $75.15 \%$ in the Sylhet division compared to the national average of $81.64 \%$. Moreover, the number of government-subsidised schools was the highest in the Sylhet division at $17 \%$ compared to the country's average of $11.89 \%$ (BBS 2011). Sylhet has migratory connections with Britain (Gardner 2008), which is the most significant reason why the district is seen as unique and different from other districts of the country. A significant rise in remittances from Bangladeshi migrants has created an opportunity for enthusiastic investment in local property and dynamic exchanges in the local market in Sylhet district (Ludden 2003). Sylhet is also an economically important city in Bangladesh in its own right, producing the largest amount of tea and gas in the country. Sylhet is a

\footnotetext{
1 The administrative units of Bangladesh are categorised as divisions, districts, and upazilas (sub-districts). Each division includes city, urban, and rural areas and is named after the major city within its jurisdiction, which also serves its administrative headquarters. Each division is further split into several districts, which are then further sub-divided into upazilas. There are eight divisions in BangladeshDhaka (capital), Chattogram (former Chittagong), Khulna, Rajshahi, Rangpur, Sylhet, Barishal (former Barisal), and Mymensingh—with a total of 64 districts and 491 upazilas. Sylhet division has four districts: Habiganj, Moulvibazar, Sunamganj and Sylhet.
} 
land of holy shrines of great religious saints and tourist attractions. The people of this region are pious, with most identifying as Muslims, and very passionate about religious festivals (Ludden 2003). The coexistence of different religions and public participation in every religious festival has marked these local people with strong feelings of friendship and solidarity.

\section{Surveyed schools and colleges}

Three schools and colleges (one public and two private) from Sylhet city were selected for this study. The public school (anonymised as 'A') was founded in 1836 and is one of the oldest schools in Sylhet. Of the two private schools and colleges chosen, one (anonymised as 'B') was established in 1973. The second (anonymised as 'C') was established in 2013. Throughout the study, the names of the educational institutions were anonymised for confidentiality reasons.

\section{Population and sample}

The total number of teachers currently employed in all institutions was determined from the websites and administrative office data of each institution. The total number of teachers in A, B and C was 51 (male-31, female-20), 43 (male-20, female-23) and 36 (male-16, female-20), respectively. We distributed the research information to the teachers of all institutions through a "participation information sheet' and a structured questionnaire. We asked teachers to complete the questionnaire and return it to the head or director of their institution by a specified date. We first collected completed questionnaires from the administrative offices of the participating institutions three weeks after the initial distribution of the questionnaire. Finally, after five visits to all institutions, with each visit taking place after three weeks, we discontinued our data collection. From our fieldwork between January and May 2020, we ultimately received 95 responses (73\%) from the selected schools and colleges, from a total distribution of 130 questionnaires. Our goal was to collect data from all teachers; however, we did not receive responses from all teachers for a number of reasons. For example, some teachers were on leave during the field visits, some were busy teaching and grading assignments and exam papers, some female teachers were on maternity leave and some were simply not interested in participating in this study. The distribution of completed questionnaires by each educational institution was 38 (male-24, female-14) for A, 33 (male-12, female-21) for B and 24 (male-14, female-10) for C.

\section{Questionnaire and data collection}

The research approach used in this study is descriptive, which is the approach most commonly used in social research as it seeks to describe situations and events in detail (Babbie 2004). Our study relied on a primary survey, an excellent way to measure attitudes and orientations (Babbie 2004). We used a self-administered questionnaire following the methodology of previous research (Haq and Ahmed 2020; 
Mugambiwa and Dzomonda 2018). The questionnaire collected information on respondents' sociodemographic characteristics (e.g. age, gender, religion, marital status), academic background in terms of SSC, HSC, and undergraduate qualifications attained (by subject), teaching experience (years) and the sections in which they teach (either SSC/HSC or both). This questionnaire also gathered information about teachers' understanding of climate change (e.g. perceived changes in temperatures and precipitation, perceived causes of climate change and experience with extreme weather events in their community), involvement in climate-related organisations and climate course completion. Specifically, the questionnaire included twenty scale items developed based on a rigorous literature review to examine teachers' perceptions of climate change in terms of importance, causes, impacts and mitigation. The twenty associated statements and their descriptive statistics are presented in Table 1. For each statement, teachers indicated their level of agreement or disagreement on a scale of 1 to 5 ( $1=$ 'do not agree at all,' $2=$ 'disagree,' $3=$ 'neutral,' $4=$ 'agree,' $5=$ 'strongly agree'). We then divided the twenty statements into four categories, with each of five statements within a single category related to perceptions of climate change in terms of importance, causes, impacts and mitigation. Among these twenty statements across all four categories, the highest mean score (4.56) was found for statement 5, which indicates that most respondents strongly agreed that 'climate change is a threat to Bangladesh'. Statement 3 received the second-highest mean response (4.51) which reveals that most respondents strongly agreed that 'climate change is also a global problem'. Regarding the causes of climate change, the highest mean (4.24) was found for statement 6, indicating broad consensus that 'human activities are causing climate change'. Regarding the impacts of climate change, the highest mean (4.48) was found for statement 13, which suggests a shared belief that 'climate change is lowering the water table'. Finally, regarding mitigating the effects of climate change, the highest mean (4.40) was found for statement 18, which reveals a widely held opinion that 'media coverage can increase public awareness of climate change'.

\section{Analysis techniques}

We used mean variations and factor analysis to assess what extent teachers' perceptions of climate change varied in terms of importance, causes, effects and mitigation. Firstly, the arithmetic mean was calculated for each statement from the sum of the scores for that statement divided by the number of respondents. A calculated arithmetic mean value close to five shows a strong tendency to agree with the statement in question; a mean close to one shows a strong tendency to disagree. The strong agreement suggests that respondents are familiar with and concerned about climate change issues; strong disagreement indicates a lack of familiarity with the subject or a tendency to not take the topic seriously (Rahman 2003). Using mean scores, we also explored differences in perceptions of climate change with respect to the differing sociodemographic characteristics of the respondents. In addition, we used factor analysis to identify some of the most important factors underlying climate-related perceptions among teachers in this study. Factor analysis is a method of 


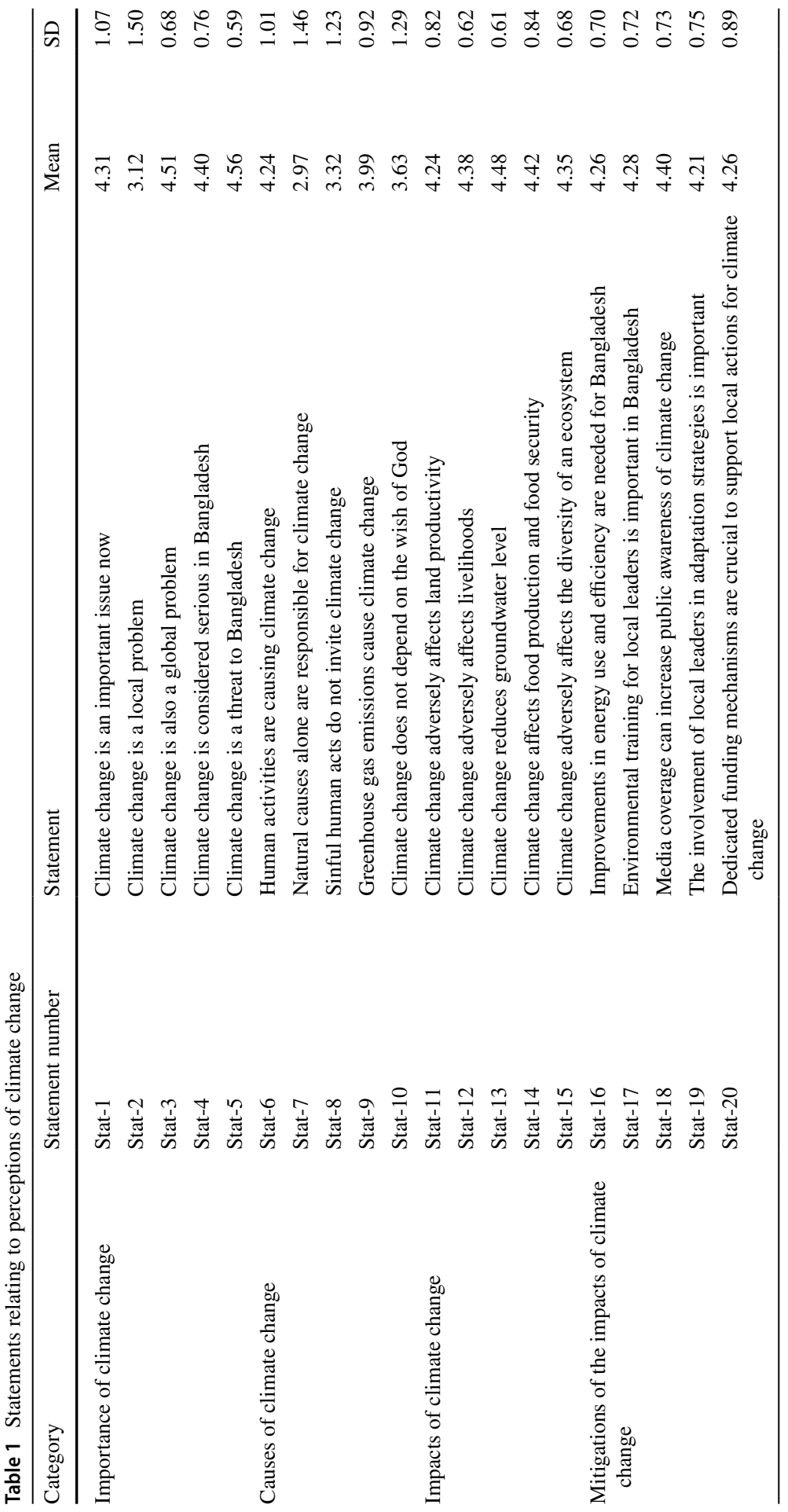


taking a mass of data and reducing it to a smaller, more consistent data set to reveal hidden patterns and reduce overlap in the data (Choon et al. 2019). We used SPSS 25 for data analysis.

We performed a binary logistic regression to examine factors that influence the level of perception of climate change. This is a popular approach to examining perceptions of climate change and adaptation strategies that has been widely used in several studies (Foguesatto and Machado 2021; Huong et al. 2017; Islam et al. 2021; Marie et al. 2020; Yamba et al. 2019). We calculated the arithmetic mean of the twenty statements selected for this study and then formed a dichotomous variable with two groups of respondents with 'high' and 'low' levels associated with their perceptions of climate change. The range of the mean score was 3.00 to 5.00. Respondents with a relatively lower mean score between 3.00 and 3.99 were grouped as 'low' (dummy ' 0 ') and those with a higher mean score between 4.00 and 5.00 were grouped as 'high' (dummy ' 1 '). For this logistic regression model, respondents with low levels of perceptions were considered as a reference group. The small sample size did not allow us to make broad categories in terms of levels associated with the respondents' perceptions of climate change and limited further multinomial logistic regression analyses. The dichotomous nature of the dependent variable and the categorical nature of the selected explanatory variables made them well-suited for binary logistic regression. A binary logistic model can be quite fruitful for analysing data in which the dependent variable has only two subcategories. The maximum likelihood technique was used to estimate the coefficients of the binary logistic regression and the factors influencing the level associated with teachers' perceptions of climate change. Model fit was verified using the Chi-square test. Overall, $72.6 \%$ of the predictions were correct, suggesting that the model estimates fit the data well and at a satisfactory level. The binary logit model estimates and the exponential of the logit regression estimate (which is shown as the predicted change in odds for a unit increase in the resulting variable) are outlined in Table 6.

\section{Results}

\section{Sociodemographic profile of respondents}

Table 2 shows the sociodemographic profiles of the respondents. In this study, $60 \%$ of participating teachers worked in private schools and colleges and $40 \%$ worked in public schools and colleges. Of the teachers, $52.6 \%$ were male, and $47.4 \%$ were female. Most of the teachers were married (77.9\%). Teachers were grouped according to their religious status: 'Islam' and 'Other'. This 'Other' group included $27.4 \%$ of teachers of Hindu, Buddhist, and Christian faiths. The ages of the teachers ranged from 24 to 59 years. Teachers aged between 24 and 50 years were grouped as 'early and mid-career' and those between 51 and 59 years as 'senior'. Most (84.2\%) of the teachers were early or mid-career. The educational level of most teachers $(83.2 \%)$ was a master's degree or higher.

Teachers were asked about their academic background in terms of SSC, HSC, and undergraduate qualifications attained, by subject. SSC and HSC students pursue 
Table 2 Sociodemographic profiles of teachers

\begin{tabular}{|c|c|c|}
\hline Characteristics & Frequency & $\%$ \\
\hline \multicolumn{3}{|l|}{ Types of school and colleges } \\
\hline Public & 38 & 40 \\
\hline Private & 57 & 60 \\
\hline \multicolumn{3}{|l|}{ Gender } \\
\hline Male & 50 & 52.6 \\
\hline Female & 45 & 47.4 \\
\hline \multicolumn{3}{|l|}{ Age } \\
\hline Early and Mid (24-50) & 80 & 84.2 \\
\hline Senior $(51-59)$ & 15 & 15.8 \\
\hline \multicolumn{3}{|l|}{ Marital status } \\
\hline Married & 74 & 77.9 \\
\hline Unmarried & 21 & 22.1 \\
\hline \multicolumn{3}{|l|}{ Religion } \\
\hline Islam & 69 & 72.6 \\
\hline Others & 26 & 27.4 \\
\hline \multicolumn{3}{|l|}{ Education } \\
\hline Bachelor's & 16 & 16.8 \\
\hline Master's or above & 79 & 83.2 \\
\hline \multicolumn{3}{|l|}{ Discipline in SSC } \\
\hline Humanities and Business & 34 & 35.8 \\
\hline Science & 61 & 64.2 \\
\hline \multicolumn{3}{|l|}{ Discipline in HSC } \\
\hline Humanities and Business & 39 & 41.1 \\
\hline Science & 56 & 58.9 \\
\hline \multicolumn{3}{|l|}{ Discipline in Bachelor } \\
\hline Humanities and Business & 57 & 60 \\
\hline Science & 38 & 40 \\
\hline \multicolumn{3}{|c|}{ Currently taking classes in sections } \\
\hline Either SSC or HSC & 73 & 76.8 \\
\hline Both SSC and HSC & 22 & 23.2 \\
\hline \multicolumn{3}{|l|}{ Teaching experiences } \\
\hline$<20$ years & 79 & 83.2 \\
\hline$>20$ years & 16 & 16.8 \\
\hline \multicolumn{3}{|c|}{$\begin{array}{l}\text { Home locality vulnerable to climate extremes } \\
\text { and disasters }\end{array}$} \\
\hline Yes & 55 & 57.9 \\
\hline No & 40 & 42.1 \\
\hline \multicolumn{3}{|c|}{ Involvement in an environmental organisation } \\
\hline Yes & 11 & 11.6 \\
\hline No & 84 & 88.4 \\
\hline \multicolumn{3}{|c|}{ Environment and disaster course completion } \\
\hline Yes & 9 & 9.5 \\
\hline No & 86 & 90.5 \\
\hline
\end{tabular}


one of three general subjects: Humanities, Business, and Science. Although participating teachers had studied a wide variety of subjects for their bachelor's and master's degrees, we categorised them into the above three subject areas for consistency. Humanities (and social science) subjects included, for example, anthropology, archaeology, economics, geography, history, law, linguistics, politics, psychology and sociology. Business subjects included management, marketing, accounting and information systems, finance, banking and insurance, tourism and hospitality management and human resource management. Finally, the natural science subjects included the broad fields of physical, applied, life and mineral sciences. For comparison purposes, we created two groups of teachers, one that included those who had studied humanities and business administration and one that included those who had studied natural sciences. About two-thirds of the teachers $(64.2 \%)$ were in the science group for their SSC exams; and for the HSC exams, this percentage dropped by about $5 \%$. It should be noted that students in the science group for the SSC can migrate to one of the other two groups for the HSC. For their bachelor's degrees, $60 \%$ fit into the humanities and economics group and $40 \%$ fit into the natural sciences group.

In terms of teaching experience, results showed that the majority had less than 20 years' experience, while $16.8 \%$ of the teachers had had over twenty years' experience. Teachers were also asked whether they taught students in SSC or HSC sections. It should be noted that teachers may take classes for one or both sections, according to institutional procedures. For example, a biology teacher may teach students from both sections. In addition, a teacher may teach more than one course at a time. Our results showed that $76.8 \%$ of teachers teach their courses for either SSC or HSC sections, and about a quarter (23.2\%) reported teaching courses for both sections.

Teachers were also asked if their location was at risk for climate extremes and disasters (hereafter referred to as 'CEDs'); according to their answers, 57.9\% indicated that their location was at risk for regular CEDs. We found that few teachers were involved in any environmental organisation or activity and fewer had attended courses on the environment and disaster management.

\section{Respondents' understandings about climate change and its importance, causes, impacts and mitigations}

\section{Understanding of climate change}

Respondents' understanding of various issues related to climate change is summarised in Table 3. We compared the understanding of climate change among teachers at public and private institutions and validated the associations through Chi-square tests. It was found that a comparatively higher number of teachers at public institutions were more familiar with the term 'climate change'. However, the association was not statistically significant. Similarly, there was no statistically significant difference in teachers' familiarity with climate change. However, we found statistically significant differences in teachers' perceptions of changes in temperature and 


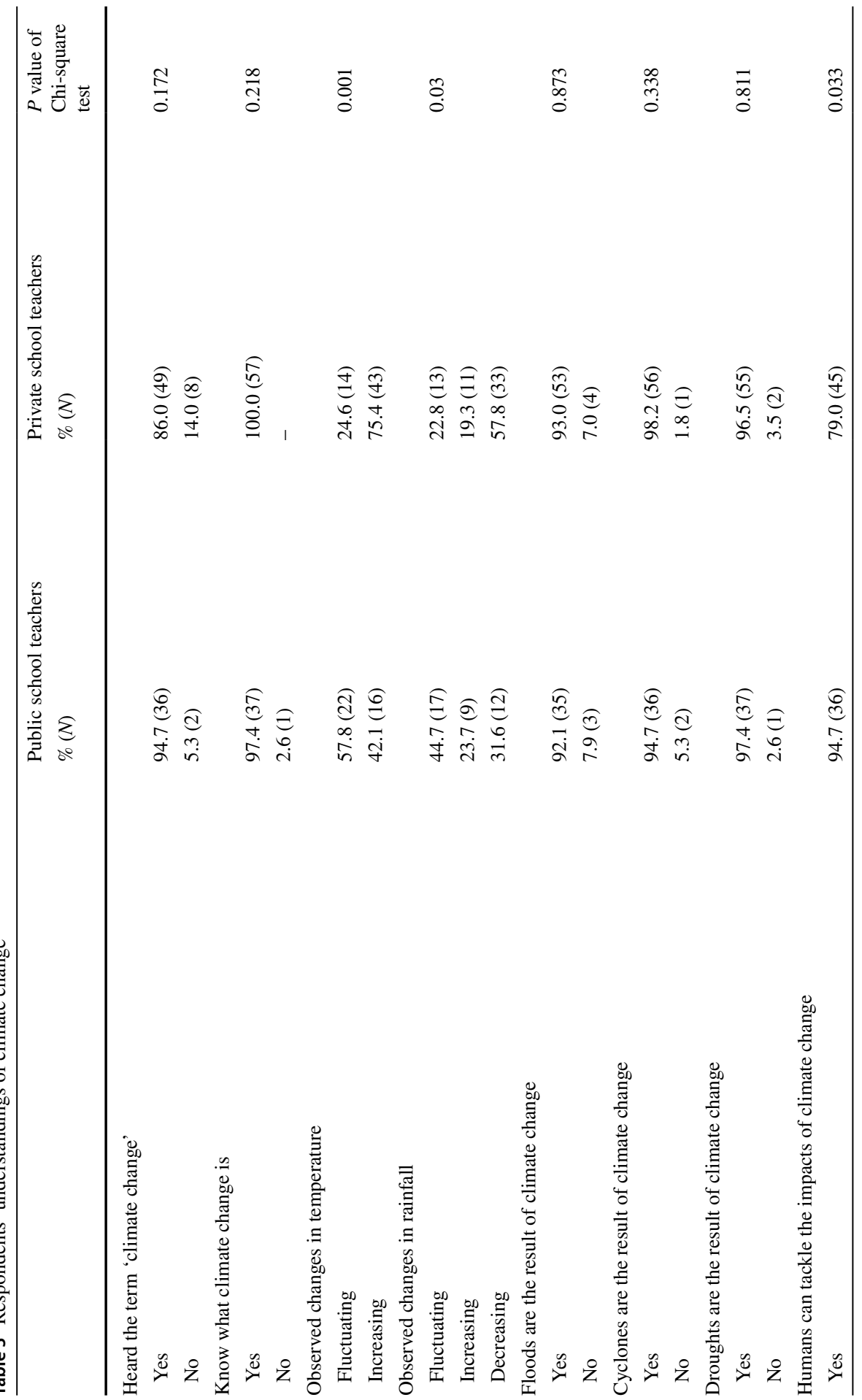

SN Social Sciences

A SPRINGER NATURE journal 


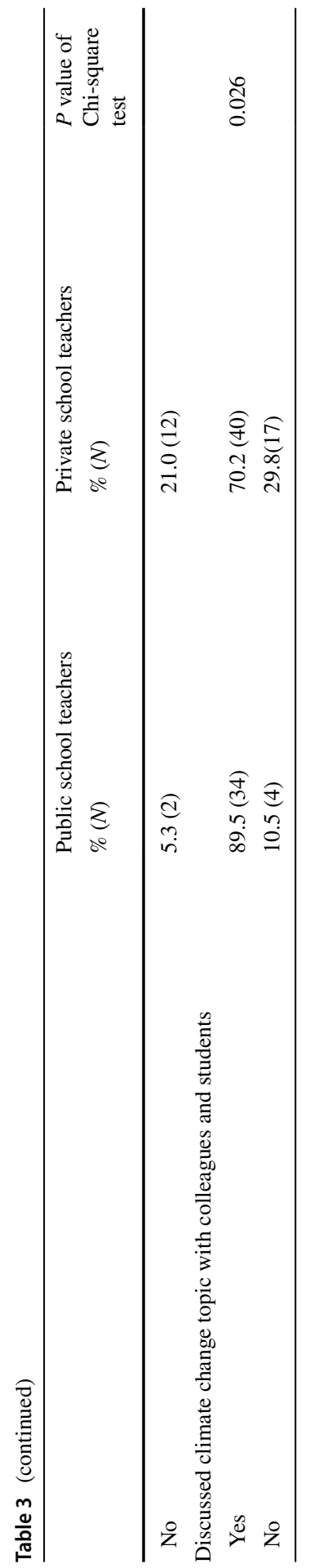


precipitation in their area. A majority of participating teachers at the public institution reported having perceived temperatures and precipitation as 'fluctuating', (57.8\% and $44.7 \%$, respectively), while the majority of teachers at the private institutions reported having perceived temperatures as 'increasing' (75.4\%) and precipitation as 'decreasing' (57.8\%). There was no significant difference in understanding among public and private school teachers regarding whether hazards such as floods, cyclones and droughts are caused by climate change or not. Teachers in both types of institution have a good understanding that humans can combat the adverse effects of climate change. While the majority of public and private school teachers also said they discuss climate change issues with their colleagues in staff meetings and with students in classrooms, it was found that more teachers at public institutions discuss this issue with their colleagues and students than those at private institutions.

\section{Importance of climate change}

Figures 1, 2, and 3 show the respondents' level of understanding based on twenty statements used to assess their perceptions of the importance of climate change and its causes, impacts and mitigation. Figure 1 shows the frequency distribution of the statements, Fig. 2 shows the mean score of the individual statements, and Fig. 3 shows the mean changes in the grouped statements with respect to the importance of climate change, and its causes, impacts and mitigations among public and private teachers.

In terms of respondents' perceptions of the importance of climate change, Fig. 1A shows that the majority of both public and private school respondents agreed with Stat-1. Higher percentages of public school respondents view climate change as a local problem (Stat-2), while most private school teachers believe it is a global problem (Stat-3). Many teachers from both types of institutions agree on Stat-4 and Stat-5 about climate change being observed in Bangladesh, and the fact that it is a threat to Bangladesh. Figures $2 \mathrm{~A}$ and 3 show the mean score for teachers' understanding of the importance of climate change in public and private schools and colleges. The results reveal that the mean score for the importance of climate change was almost the same for public and private school teachers, indicating their shared profound concerns around this issue.

\section{Causes of climate change}

Figure 1B shows that most teachers at both public and private institutions agreed with Stat-6, that human activities cause climate change. More public than private school teachers agreed that only natural causes are responsible for climate change (Stat-7), and that sinful human acts do not invite climate change (Stat-8). We noted similar responses from both groups to Stat-9 and Stat-10. This indicates that both groups of teachers believe that greenhouse gas emissions cause climate change, and that climate change is not dependent on God's will. The results presented in Figs. 2B and 3 show that public school teachers were more aware of the causes of climate change than their private school counterparts. 


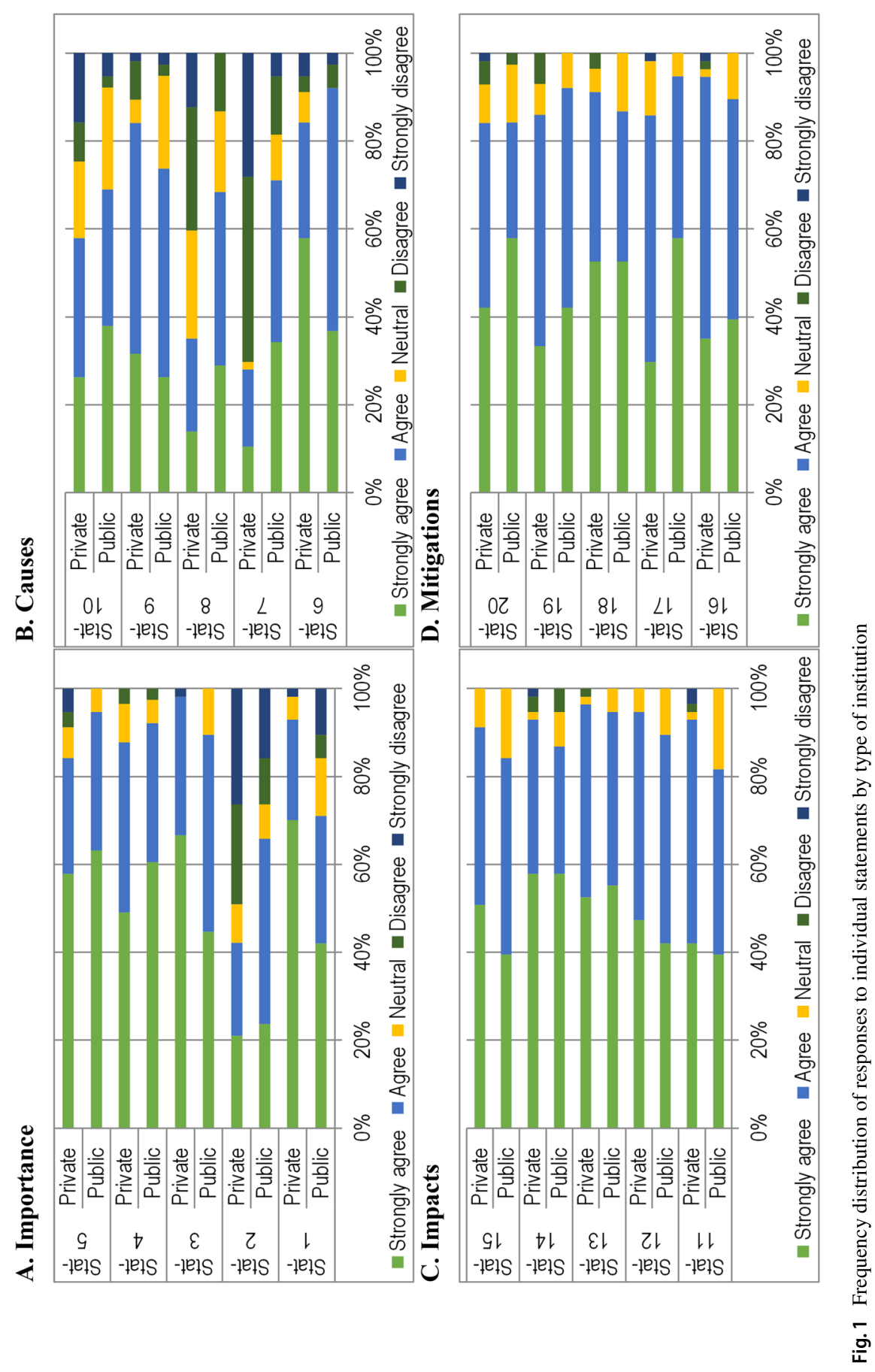




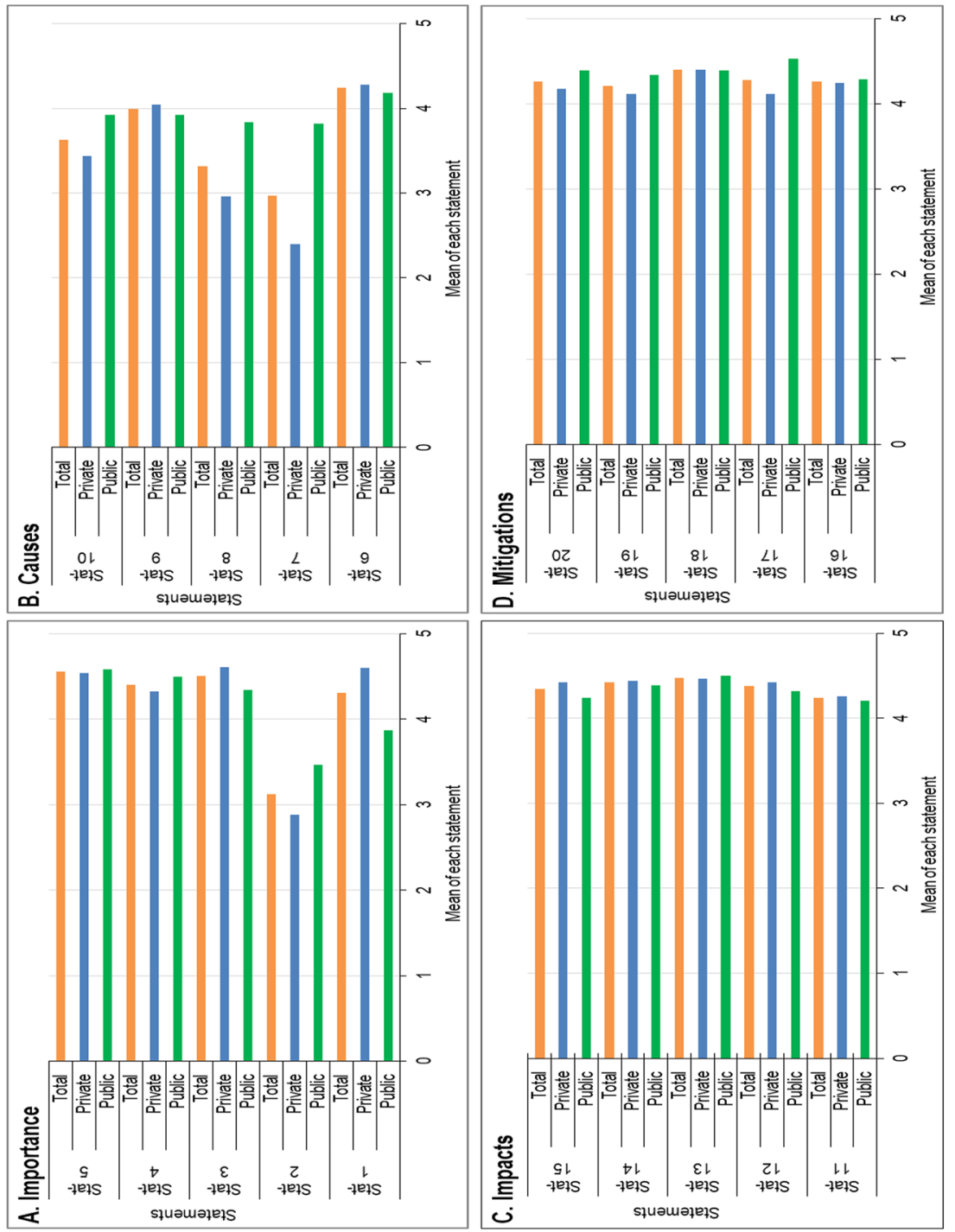

告 


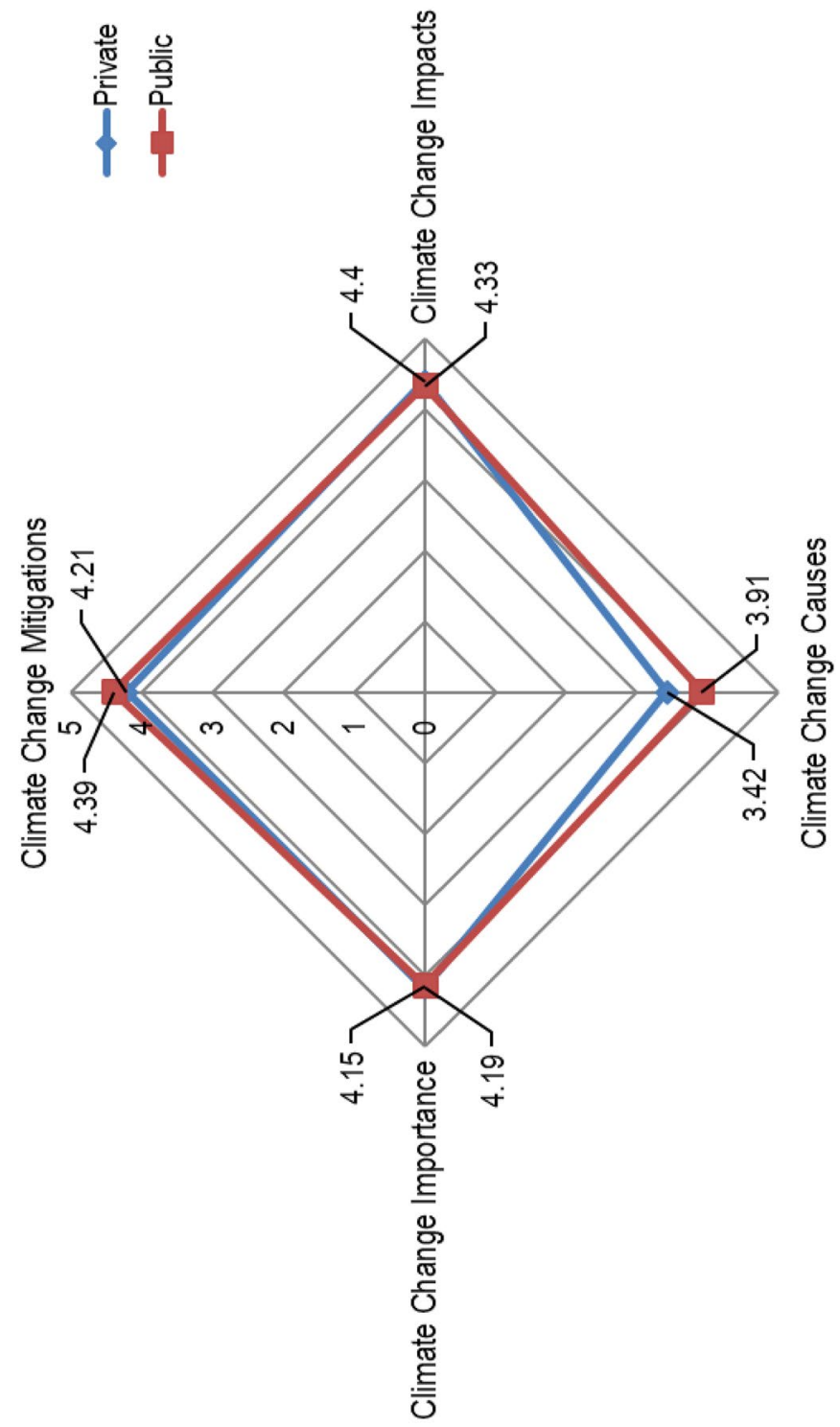

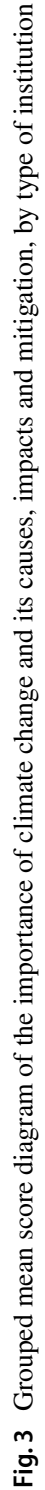




\section{Impacts of climate change}

Figure 1C shows that most public and private school teachers had a good understanding of the impacts of climate change. Their responses suggest that these teachers recognised that climate change adversely affects land productivity (Stat-11), livelihoods (Stat-12), food production and food security (Stat-14), ecosystem diversity (Stat-15) and groundwater levels (Stat-13). The observed differences in the mean scores of the individual statements and the grouped scores were negligible (Figs. 2C and 3). This result is a clear indication of the teachers' understanding of the impacts climate change can have on nature and society.

\section{Mitigation of climate change}

According to their responses to the questionnaire, teachers at participating public and private institutions in Sylhet demonstrated having a similar understanding of climate change mitigation (Figs. 1D, 2D, and 3). Teachers largely agreed with statements highlighting strategies to mitigate climate change that call for: improving energy use and efficiency (Stat-16), training local leaders on the environment and disasters (Stat-17), facilitating the role of the media in increasing public awareness of climate change (Stat-18), engaging local leaders in adaptation and mitigation strategies (Stat-19) and improving dedicated funding mechanisms to support local climate change actions (Stat-20).

\section{Sociodemographic dimensions and perceptions of climate change}

In this study, respondents' perceptions of the importance of climate change and its causes, impacts and mitigation were examined using a combination of sociodemographic dimensions presented in Table 4. This table shows that the mean scores associated with female respondents were higher than that of males across all factors, indicating that females were more concerned about climate change than males. The mean scores also suggest that married teachers were more concerned about the causes, consequences and mitigation of climate change, while unmarried teachers were primarily concerned about the importance of climate change. Religion also proved to be an important determinant of perceptions of climate change. Our results suggest that teachers practising 'other' religions were more likely to have high mean scores in terms of their perceptions of climate change. Older teachers were more concerned about the impacts of climate change and its mitigation. This may result from the fact that older teachers have experience with the adverse effects of climate extremes and disasters and with adaptation and mitigation strategies. By contrast, early- and mid-career teachers were more likely to be concerned about the importance and causes of climate change. Teachers with higher levels of education (holding a master's degree or higher) had higher mean scores for the importance, causes and consequences of climate change. Teachers with a science background in their SSC, HSC and bachelor's/master's degrees had higher mean scores of the 


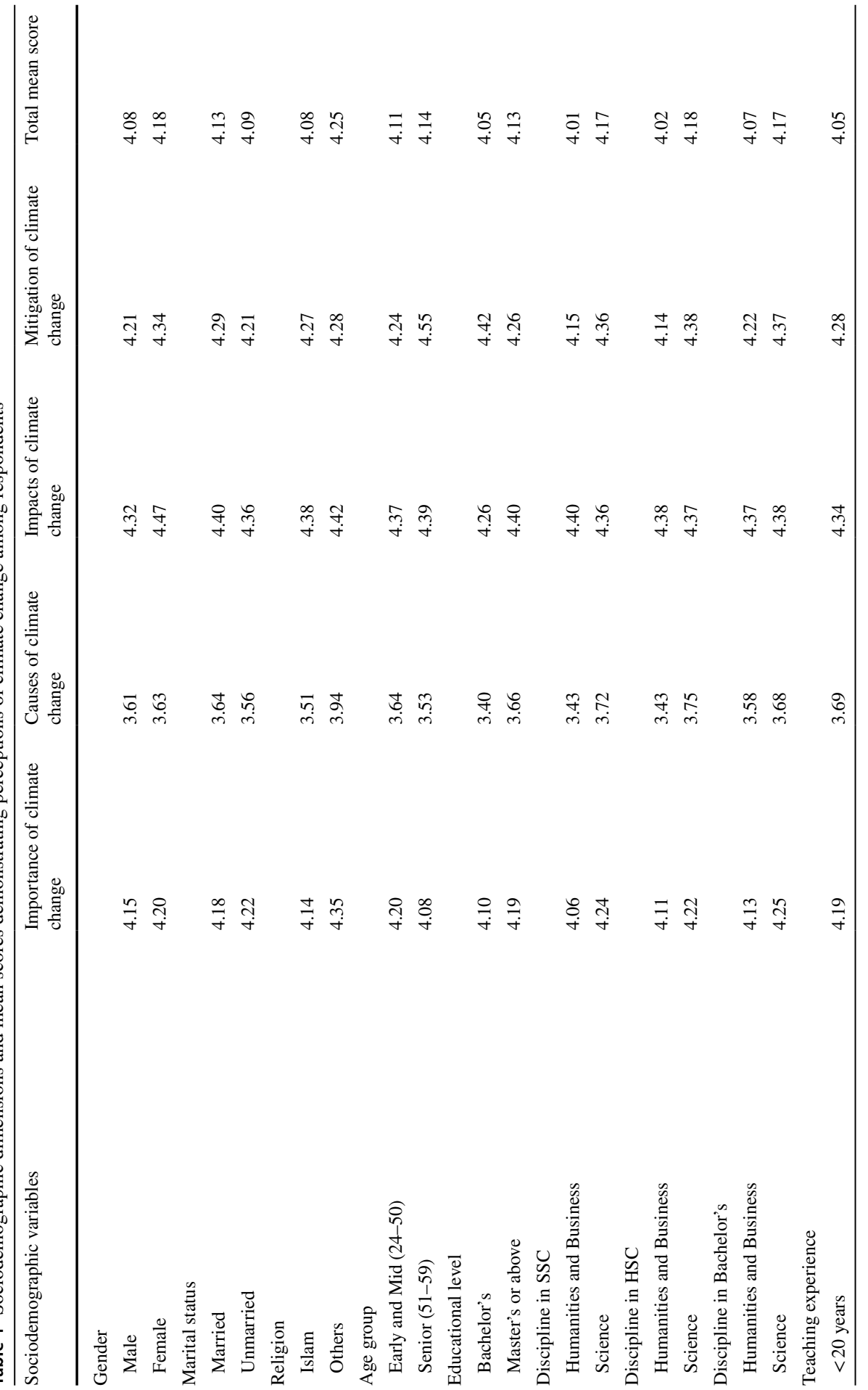




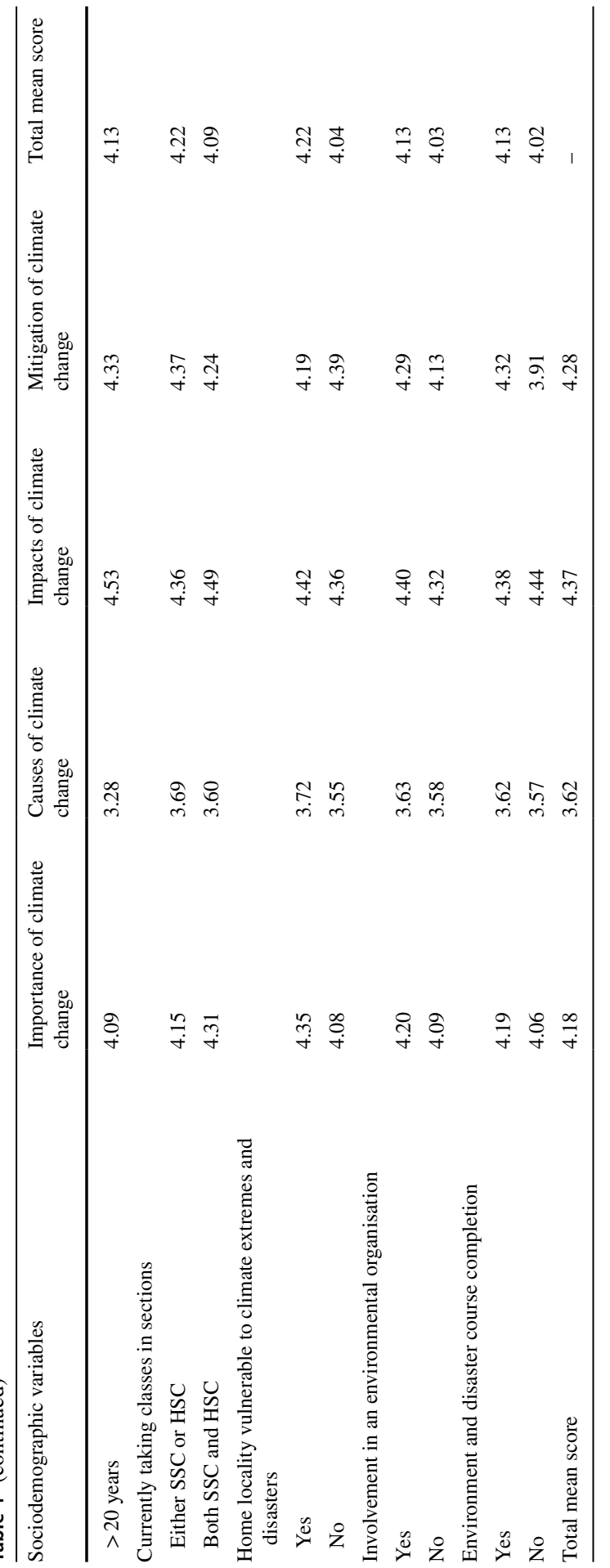

SN Social Sciences

A SPRINGER NATURE journal 
importance, causes and mitigation of climate change than teachers who had studied humanities, social sciences, or business. Overall, results from teachers with a science background revealed that they shared a high level of awareness and understanding of climate change.

It was assumed that their number of years of teaching experience could affect teachers' perceptions of climate change. Our overall results suggest that teachers with a greater number of years of teaching experience had a higher level of awareness and understanding of climate change. The overall mean score was higher for teachers teaching either SSC or HSC than for those teaching both sections; these SSC/HSC teachers demonstrated more significant concerns with the causes and mitigations of climate change. This difference might be explained by the fact that teachers teaching both SSC and HSC sections are more likely to take classes in common subjects such as English, Bengali, mathematics and general knowledge, rather than specialise in subjects such as agricultural studies, geography and Bangladesh and global studies. Teachers who believed that their home locality was vulnerable to climate extremes and disasters scored higher on the importance, impacts and consequences of climate change. A higher mean score for teachers participating in an environmental organisation indicated that they had a greater awareness and understanding of climate change. Teachers who had completed courses on the environment and disasters also had higher overall mean scores, particularly in terms of the importance, causes and mitigation of climate change.

\section{Perceptions of climate change: factor analysis}

This study explains teachers' perceptions of climate change by examining twenty statements on a five-point scale. Factor analysis across these statements was used to provide more information about participating teachers' perceptions of climate change, and the results are shown in Table 5. The Cronbach's alpha score of 0.697 suggests that the scale items were reliable for factor analysis, as a Cronbach's alpha of greater than 0.5 is acceptable. The Kaiser-Meyer-Olkin ((KMO) value of 0.586 indicates that the sampling suitability of the scale items was acceptable and that the data was suitable for factor analysis. Factor analysis extracts six components or factors by counting the factor extraction process on the score of the most significant eigenvalue of more than one. Finally, the rotated component matrix helps interpret the six components by rotating the best performing items in each component.

The first factor consists of six highly loaded elements (Stats 6, 8, 12, 13, 14, 15). This first factor suggests that teachers believe climate change results from human activity, but that 'sinful' human activity is not responsible for climate change. This first factor also highlights several consequences of climate change that participating teachers believe affect different areas of life. Teachers believe that climate change lowers the water table, affects food production, negatively impacts livelihoods, and reduces the diversity of an ecosystem.

Factor two is heavily loaded with four items (Stats 16, 17, 18, 19), the answers to which indicate a broader consensus around the mitigation of climate change in Bangladesh. This factor suggests that teachers believe both improved energy consumption 


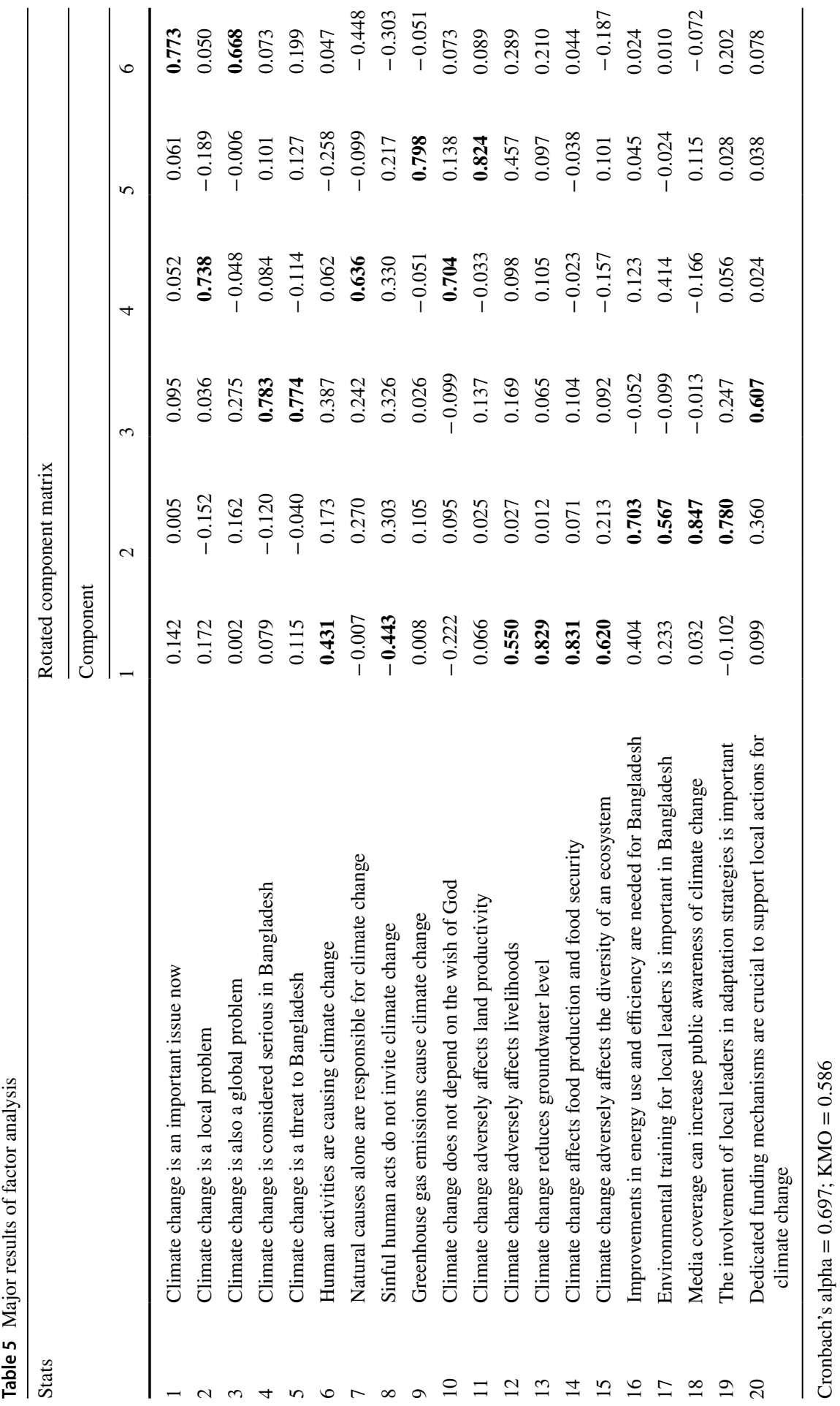


and efficiency and the environmental education of influential local leaders and their engagement in adaptation strategies are essential for climate change mitigation in Bangladesh. In addition to emphasising the role of local leaders, teachers agree that media coverage could play a crucial role in raising awareness of climate change among the masses.

Three statements (Stats 4, 5, 20) have been weighted by the factor of three. This third factor suggests that climate change is being seriously monitored in Bangladesh and poses a significant threat. Dedicated funding is deemed essential to support local action against climate change.

Factor four includes three heavily loaded statements (Stats 2, 7, 10). This factor tells us that teachers perceive that climate change is monitored at the local level, natural causes are responsible for climate change and climate change is not God's wish.

Factor five, with two heavily loaded statements (Stats 9 and 11), implies that teachers consider greenhouse gas emissions to cause climate change and that this change in climate reduces the earth's production.

Finally, factor six contains two statements (Stats 1 and 3) that reveal teacher perceptions that climate change is a major issue and a global problem.

\section{Significant factors affecting the perception of climate change: binary logistic regression}

We performed a binary logistic regression model to explore the factors that significantly influence teachers' overall level of awareness and understanding of climate change. The explanatory variables and their reference groups are explained in Table 6 . This model explained $23.2 \%$ of the variance and showed that only two predictors were significant in explaining the level of the teachers' awareness and understanding of climate change. However, most of the other predictors were also noteworthy in explaining the variation in teachers' perceptions of climate change. The two significant predictors were gender and the sections in which teachers taught. The model shows that males were less likely to have high levels of awareness and understanding of climate change. In other words, women's measured perceptions of climate change were at a higher level than those of men. In addition, teachers who taught in both the SSC and HSC sections were 5.9 times more likely to have high levels of awareness and understanding of climate change than teachers who only taught in one of the sections. This indicates that teachers who taught courses in different sections had developed a greater understanding of different topics, including, but not limited to, climate change.

The results of other explanatory variables have further implications for understanding teachers' perceptions of climate change. For example, although the variable 'type of institution' was not significant, the odd ratio suggests that teachers in public institutions were 3.4 times more likely to have high levels associated with their perceptions of climate change than teachers in the private institutions. In terms of age, younger teachers were 1.7 times more likely to have high levels of awareness and understanding of climate change than middle-aged and older teachers. In addition, teachers with higher levels of education (e.g. master's degree and above) were more 
Table 6 Parameter estimates for levels associated with teachers' perceptions of climate change

Types of institution

Public (ref= Private)

Gender

Male (ref =Female)

Age

Young (ref = Middle-aged and Older)

Marital status

Married (ref $=$ Unmarried)

Religion

Islam (ref= Others)

Education

Master's and above (ref=Bachelor's)

Disciplines in SSC

Science (ref=Humanities \& Business)

Disciplines in HSC

Science (ref= Humanities \& Business)

Disciplines in Bachelor

Science (ref = Humanities \& Business)

Currently taking classes in sections

Both SSC and HSC (ref = either SSC or HSC)

Years of Teaching Experience

$<20$ years $($ ref $=>20$ years $)$

Home locality vulnerable to climate extremes and disasters

$$
\text { Yes (ref }=\text { No) }
$$

Involvement in an environmental organisation

Yes (ref = No)

Environment and disaster course completion

Yes $(\mathrm{ref}=\mathrm{No})$

Reference category: Low perception

Observation $=95 ;$ Chi-square $=17.523 ; \mathrm{R}^{2}($ Nagelkerke $)=23.2 \% ;$ Classification $=72.6 \%$

$* * * p<0.005, * * p<0.010, * p<0.05$

likely to know more about climate change than teachers with a bachelor's degree. The odd ratio of teachers to their science discipline in SSC is nearly 7. This means that teachers who had a science discipline on their SSC exams were 7 times more likely to have higher levels associated with their climate change perceptions than teachers with humanities and business backgrounds. HSC and bachelor-level disciplines had negative associations in terms of their perceptions of climate change. In addition, other predictors, such as years of teaching experience, having experienced or not experienced an extreme weather event in their hometowns, and being involved 
in an environmental organisation, had negative associations with levels of climate change perceptions. Finally, completing a climate change course had a positive association with teachers' levels of understanding. Levels of understanding of climate change were 3.3 times higher for teachers who had taken a climate change course.

\section{Concluding discussions}

The study focuses on how teachers' perceptions of climate change vary in terms of its importance, causes, effects and mitigation and compares the responses of public and private school and college teachers in Sylhet, Bangladesh. The study shows that most of the participating teachers in the public and private schools and colleges surveyed knew the term 'climate change' and understood its meaning. This finding contradicts the study by Anik and Khan (2012) which revealed that few respondents were familiar with climate change, and is in line with the findings of Asia Foundation (2012) research investigating the perceptions of climate change in five at-risk areas in Bangladesh, which found that the majority of the population had heard of the term 'climate change'. Other studies exploring perceptions of climate change conducted in different countries have produced similar results demonstrating awareness of the term (Abegaz and Wims 2015; Ahmed and Haq 2019; Haq and Ahmed 2017; Higde et al. 2017; Kabir et al. 2016; Meilinda et al. 2017; Yu et al. 2013).

We asked teachers to indicate their observations of changes in temperature and precipitation (increase/decrease), and they responded with mixed opinions. Most private school teachers described temperature as 'increasing' and precipitation as 'decreasing'. In contrast, most public school teachers chose to define both temperature and precipitation as 'fluctuating'. These perceptions of temperature and precipitation changes among teachers at private institutions are consistent with findings from previous studies. Observations of increasing temperature and decreasing annual precipitation are two of the most common findings of international studies of perceptions of climate change studies, as demonstrated in studies by: Haq and Ahmed (2020) in Bangladesh; Manandhar et al. (2014) in Thailand; Shukla et al. (2015) in India; Debela et al. (2015) in Ethiopia; and Brüssow et al. (2019) in Tanzania. According to the responses of participating teachers to our questionnaire, it is evident that most teachers from the public and private schools and colleges surveyed believe that certain natural disasters, such as floods, cyclones and droughts are the result of climate change; they also discuss climate change issues with their peers. The Asia Foundation (2012) also found that most Bangladeshi residents believe that climate change means floods and/or heavy rains; more than one-third of the respondents in the Asia Foundation (2012) study said climate change means storms/ cyclones, while less than one-quarter saw climate change as a cause of drought. Findings of our study show that the public school teachers in our sample were more likely to believe that humans can cope with the effects of climate change than private school teachers.

Regarding the importance of climate change (statements 1-5), we found that most teachers from both types of schools and colleges considered climate change an important issue. The average score shows that teachers from private schools were 
significantly more likely to consider climate change an important issue than teachers from public schools. According to our study, public school respondents generally believe that climate change is a local problem, while private school respondents believe it is a global problem. Ahmed and Haq (2019) conducted their research among indigenous people of Bangladesh and found that most of their respondents did not agree that climate change was a local problem. In contrast, we found that a high percentage of teachers from both public and private schools believed that the effects of climate change can be seen in Bangladesh, and that climate change threatens the country.

Regarding the causes of climate change (statements 6-10), this study shows that both public and private school teachers blamed human activities, rather than 'God's will' for climate change. However, the mean scores showed that public school teachers were more likely than private school teachers to consider climate change to be a result of natural causes, rather than sinful human actions. In contrast, more private school teachers than public school teachers agreed that greenhouse gas emissions cause climate change. The acknowledgement of human activities as reasons for climate change have also been documented in many international studies (Ahmed and Haq 2019; Kabir et al. 2016; Meilinda et al. 2017; Shi et al. 2016). In contrast, climate change is also believed by some peoples to be an act of God, as a response to the sins of humanity (Abegunde 2017; Debela et al. 2015). At the same time, according to Lorenzoni et al. (2007), it appears that a large proportion of the population does not believe that climate change is caused by humans.

Regarding the impacts of climate change (statements 11-15), this study found that participating teachers from both public and private schools and colleges mostly agreed that climate change has a negative impact on land productivity, livelihoods, groundwater levels, food production, and the diversity of an ecosystem. However, taking a closer look at the average score reveals a difference in opinion among teachers. Private sector teachers were more likely to perceive the effects of climate change on land productivity, livelihoods, food production and ecosystem diversity, while public sector teachers were more likely to most strongly perceive the effects of climate change on groundwater levels. Relevant statements were strongly loaded in factor one and five of the factor analysis, showing the adverse effects of climate change on various sectors of our lives. Many other researchers have also shown that climate change affects many aspects of local life, by causing water problems, loss of agricultural productivity due to diseases and pests, loss of income and degraded public health (Akter and Bennett 2011; Meilinda et al. 2017; Prokopy et al. 2015).

This study also examined respondents' perception of strategies to mitigate the effects of climate change (Statements 16-20), and shows that both public and private school and university teachers surveyed believe that improvements in the use and efficiency of energy must be made in Bangladesh to mitigate the effects of climate change. Teachers from both types of schools and colleges also demonstrated their understanding that the training and involvement of local leaders are essential to adaptation strategies. Of the five statements, four statements, excepting statement twenty, were heavily loaded into factor four, with similar answers. Most participating teachers indicated a belief that earmarked funding and media can play a significant role in raising public awareness to mitigate the effects of climate change. 
However, the mean reveals that private school teachers responded most strongly to the mitigating strategies of improving energy use and energy efficiency. In contrast, public school teachers responded to the mitigation strategies of training and increasing the participation of local managers and of funding such measures at the local level. The mean response regarding the role of the media in raising awareness of climate change among the masses was relatively close for both school/university types. Studies conducted in different parts of the world also found similar results, with respondents saying they wanted to reduce energy and gasoline consumption (Semenza et al. 2008) and increase the responsibility of government and people and amplify the role of the mass media (Ahmed and Haq 2019). As lack of funds, government support and adequate information are identified as the main barriers to action against climate change (Akhtar et al. 2019), awareness of climate change is vital to the mitigation of its effects (Akter and Bennett 2011).

The respondents' perceptions of climate change were also examined in terms of sociodemographic dimensions, academic disciplines and experiences with climate change. The logistic regression model found gender to be a significant predictor of climate change awareness and understanding. This model shows that women are more aware of climate change than men. This finding aligns with other studies that confirm that women perceive climate change more scientifically than men (Abegaz and Wims 2015; McCright 2010; Pandve and Raut 2011). In addition, this model confirms that teachers who have taught courses in different sections have developed a better understanding of various topics, including, but not limited to, climate change. This could be due to the fact that these teachers deliver lessons addressing a large number of environmental and disaster-related topics included in subjects like 'Agricultural Studies' and 'Bangladesh and Global Studies' in the SSC sections (Islam 2021). The results of other explanatory variables have further implications for understanding teachers' perceptions of climate change. Teachers who are married and practice Islam were less likely to have a high awareness of climate change. Young teachers who had higher levels of education, taught science in the SSC section and completed environmental and disaster courses were more likely to have a high level of awareness of climate change. Our result is very similar to the findings of the study by Eze (2020) in Nigeria, in which a teacher's academic discipline was considered necessary to explain the teacher's awareness of climate change and their willingness to be environmentally friendly. In this study in Nigeria, science teachers demonstrated a greater awareness of climate change than their peers in social science and arts. In comparison, social science teachers earned a higher average 'environmental willingness' score than teachers of other university-level disciplines. Additionally, teachers with a master's degree had a higher average score for climate change awareness than teachers with a bachelor's degree (Eze 2020).

In our study, according to our binary logistic regression, teachers with a greater amount of teaching experience also were more likely to have a higher result in terms of their perception of climate change. Surprisingly, teachers whose home locality was vulnerable to climate extremes and disasters were less likely to have a high level of awareness and understanding of climate change. Also, involvement in an environmental organisation and activities lead to a lower result in terms of perceptions of climate change. This result could be associated with their activities performed 
in the engaged organisation, which went beyond the scope of the research and can be explored further in future research. Not surprisingly, the completion of environment and disaster courses resulted in a higher odds ratio to explain a higher level of perception of climate change. Most of our findings are in line with previous research concluding that personal experience with climate extremes and disasters, academic course completion related to environment and disasters and an individual's engagement with environmental organisations and activities shape their perception of climate change (Eze 2020; Fernandino et al. 2019; Haq and Ahmed 2017, 2020).

How teachers see something is fundamental to shaping their students' ideas about it. Indeed, students learn more than just their subject content from their teachers, and teachers who see climate change as an important issue that affects them locally and nationally will certainly try to make their students aware of it. This paper was an attempt to show the variation in the perceptions of climate change among private and public teachers in Bangladesh. Based on the findings from our logistic regression model, we can conclude that participating teachers of public institutions were more likely to have a higher awareness and understanding of the importance, causes, impacts and mitigation of climate change than their counterparts in private schools and colleges. In Bangladesh, private school teachers strictly follow prearranged syllabuses when they provide lessons; merely following the syllabuses leaves little or no space for teacher autonomy. In contrast, public school teachers have more freedom in their lesson planning and receive government-facilitated learning and training opportunities. Therefore, public teachers can obtain knowledge that can shape their perceptions, which can then be incorporated into their class practice (Tehrani and Mansor 2012). The results of this study suggest that introducing and implementing courses and practical training for both public and private teachers related to the environment, climate change and disaster management can significantly influence the perceptions and mitigation and adaptation behaviours of participating teachers.

This study seeks to fill a gap in the research into teachers' perceptions of the importance, causes, impact and mitigation of climate change by taking Bangladesh as a case. It is hoped that our observations will help create a framework for others to make comparisons of the perceptions and experiences of climate change and its consequences in other places, among different key groups. A significant empirical implication of our findings is that teachers should be included and trained in local climate change-related disaster management programmes to help them build a solid understanding of climate change that they could then pass on to their students.

This document is not self-contained, as it does not offer comprehensive information and data; a number of limitations, including the unprecedented impact of Covid-19, have reduced our opportunity for detailed investigation and data collection on a larger scale. Further study of the teachers of tertiary institutions and universities in Bangladesh would contribute to the development of a more sophisticated picture of teacher perceptions of climate change in this country. Conducting further research on this subject could also reinforce the status of similar research questions and increase the likelihood that the results will be considered in policy development within agendas for global disaster management. 
Data availability All raw data used in this project is confidential.

\section{Declarations}

Conflict of interest All authors do not have any conflicts of interest.

Informed consent All respondents gave us their consent.

\section{References}

Abegaz DM, Wims P (2015) Extension agents' awareness of climate change in Ethiopia. J Agric Educ Ext 21(5):479-495

Abegunde AA (2017) Local communities' belief in climate change in a rural region of Sub-Saharan Africa. Environ Dev Sustain 19:1489-1522

Ahmed MNQ, Haq SMA (2019) Indigenous people's perceptions about climate change, forest resource management, and coping strategies: a comparative study in Bangladesh. Environ Dev Sustain 21:679-708

Akanda MGR, Howlader MS (2015) Coastal farmers' perception of climate change effects on agriculture at Galachipa upazila under Patuakhali district of Bangladesh. Glob J Sci Front Res 15(4):30-39

Akhtar R, Masud MM, Afroz R (2019) Perception of climate change and the adaptation strategies and capacities of the rice farmers in Kedah, Malaysia. Environ Urban ASIA 10(1):99-105

Akter S, Bennett J (2011) Household perceptions of climate change and preferences for mitigation action: the case of the carbon pollution reduction scheme in Australia. Clim Change 109:417-436

Alves F, Nicolau LB, Lima D, Azeiteiro UM, Nicolau PB (2018) University students' perceptions about climate change: the case of interior design and architecture students of a Brazilian University. In: Filho WL, Manolas E, Azul A, Azeiteiro U, McGhie H (eds) Handbook of climate change communication. Climate change management series, vol 2. Springer, Cham, pp 183-203

Anik SI, Khan MASA (2012) Climate change adaptation through local knowledge in the north eastern region of Bangladesh. Mitig Adapt Strat Glob Change 17(8):879-896

Asadullah MN (2009) Returns to private and public education in Bangladesh and Pakistan: a comparative analysis. J Asian Econ 20(1):77-86

Aslam M (2007) The quality of school provision in Pakistan: are girls worse off? GPRG working paper no. 066. University of Oxford

Babbie E (2004) The practice of social research. Thomson Learning, Belmont

BANBEIS (2006) National education survey (post-primary)-2005: Final report. Bangladesh Bureau of Educational Information and Statistics, Dhaka

BANBEIS (2011) Pocket book on education statistics. Bangladesh Bureau of Educational Information and Statistics, Dhaka

Bangay C, Blum N (2010) Education responses to climate change and quality: two parts of the same agenda? Int J Educ Dev 30(4):359-368

Bangladesh Bureau of Statistics (2011) Bangladesh Household Income and Expenditure Survey 2010. Dhaka, Bangladesh: Statistics Division, Ministry of Planning, Government of Bangladesh. http:// www.bbs.gov.bd/site/page/648dd9f5-067b-4bcc-ba3845bfb9b12394/. Accessed May, 2021

Bangladesh Bureau of Statistics (2019) Bangladesh Household Income and Expenditure Survey 2016. Dhaka, Bangladesh: Statistics Division, Ministry of Planning, Government of Bangladesh. http:// www.bbs.gov.bd/site/page/648dd9f5-067b-4bcc-ba3845bfb9b12394/. Accessed May, 2021

Bangladesh Bureau of Statistics (2021) Statistical Yearbook Bangladesh 2020. Statistics Division, Dhaka, Bangladesh: Statistics Division, Ministry of Planning, Government of Bangladesh. http://www.bbs. gov.bd/site/page/29855dc1-f2b4-4dc0-9073f692361112da/. Accessed May, 2021

Barua U, Akhter M, Ansary M (2016) District-wise multi-hazard zoning of Bangladesh. Nat Hazards 82(3):1895-1918

Brüssow K, Gornott C, Faße A, Grote U (2019) The link between smallholders' perception of climatic changes and adaptation in Tanzania. Clim Change 157:545-563 
Bryan LA (2003) Nestedness of beliefs: examining a prospective elementary teacher's belief system about science teaching and learning. J Res Sci Teach 40:835-868

Cameron S (2011) Whether and where to enrol? Choosing a primary school in the slums of urban Dhaka, Bangladesh. Int J Educ Dev 31(4):357-366

Choon SW, Ong HB, Tan SH (2019) Does risk perception limit the climate change mitigation behaviors? Environ Dev Sustain 21:1891-1917

Chowdhury R, Sarkar M (2018) Education in Bangladesh: changing contexts and emerging realities. In: Chowdhury R, Sarkar M, Mojumder F, Roshid M (eds) Engaging in educational research. Education in the Asia-Pacific Region: issues, concerns and prospects, vol 44. Springer, Singapore

Crona B, Wutich A, Brewis A, Gartin M (2013) Perceptions of climate change: linking local and global perceptions through a cultural knowledge approach. Clim Change 119:519-531

Debela N, Mohammed C, Bridle K, Corkrey R, McNeil D (2015) Perception of climate change and its impact by smallholders in pastoral/agropastoral systems of Borana. South Ethiopia Springerplus 4:236

Ding D, Maibach EW, Zhao XQ, Roser-Renouf C, Leiserowitz A (2011) Support for climate policy and societal action are linked to perceptions about scientific agreement. Nat Clim Chang 1:462-466

Directorate of Primary Education (DPE) (2016) Annual primary school census 2016. Dhaka, Bangladesh: Ministry of Primary and Mass Education, Government of the People's Republic of Bangladesh

Eze E (2020) Socio-graphic analysis of climate change awareness and pro-environmental behaviour of secondary school teachers and students in Nsukka Local Government Area of Enugu State, Nigeria. Int Res Geogr Environ Educ 29(1):89-105

Fernandino G, Elliff CI, Sousa JHO, Frutuoso GA, Gama GS, Albuquerque IS (2019) Public perceptions of climate change: a case study with school teachers and undergraduate students in Brazil. Weather 74:320-325

Foguesatto CR, Machado JAD (2021) What shapes farmers' perception of climate change? A case study of southern Brazil. Environ Dev Sustain 23:1525-1538

Gardner K (2008) Security, place, and social capital in a 'Londoni' village in Sylhet. J R Anthropol Inst 14(3):477-495

Giddens A (2009) The politics of climate change. Polity, Cambridge

Gorst A, Dehlavi A, Groom B (2018) Crop productivity and adaptation to climate change in Pakistan. Environ Dev Econ 23:679-701

Habiba U, Abedin MA, Shaw R (2013) Disaster education in Bangladesh: opportunities and challenges. In: Shaw R, Mallick F, Islam A (eds) Disaster risk reduction approaches in Bangladesh. Disaster risk reduction (methods, approaches and practices). Springer, Tokyo, pp 307-330

Haq SMA, Ahmed KJ (2017) Does the perception of climate change vary with the sociodemographic dimensions? A study on vulnerable populations in Bangladesh. Nat Hazards 85:1759-1785

Haq SMA, Ahmed KJ (2020) Perceptions about climate change among university students in Bangladesh. Nat Hazards 103:3683-3713

Herman BC, Feldman A, Vernaza-Hernandez V (2017) Florida and Puerto Rico secondary science teachers' knowledge and teaching of climate change science. Int J Sci Math Educ 15:451-471

Hess DJ, Collins BM (2017) Climate change and higher education: assessing factors that affect curriculum requirements. J Clean Prod 170(1):1451-1458

Higde E, Oztekin C, Sahin E (2017) Turkish pre-service science teachers' awareness, beliefs, values, and behaviours pertinent to climate change. Int Res Geogr Environ Educ 26(3):253-263

Ho L-C, Seow T (2017) Disciplinary boundaries and climate change education: teachers' conceptions of climate change education in the Philippines and Singapore. Int Res Geogr Environ Educ 26(3):240-252

Hossain N, Hassan M, Rahman M, Ali K, Islam M (2019) The politics of learning reforms in Bangladesh. In: Hickey S, Hossain $\mathrm{N}$ (eds) The politics of education in developing countries: from schooling to learning, 1st edn. Oxford University Press, Oxford, pp 64-85

Huda M (2013) Understanding indigenous people's perception on climate change and climatic hazards: a case study of Chakma indigenous communities in Rangamati Sadar Upazila of Rangamati District, Bangladesh. Nat Hazards 65:2147-2159

Huong NTL, Bo YS, Fahad S (2017) Farmers' perception, awareness and adaptation to climate change: evidence from northwest Vietnam. Int J Clim Chang Strateg Manag 9(4):555-576 
Hussain M, Butt AR, Uzma F, Ahmed R, Rehman A, Ali MU, Ullah H, Yousaf B (2019) Divisional disparities on climate change adaptation and mitigation in Punjab, Pakistan: local perceptions, vulnerabilities, and policy implications. Environ Sci Pollut Res 26:31491-31507

Hussain M, Butt AR, Uzma F, Ahmed R, Irshad S, Rehman A, Yousaf B (2020) A comprehensive review of climate change impacts, adaptation, and mitigation on environmental and natural calamities in Pakistan. Environ Monit Assess 192:48

IPCC (2014) Climate Change 2013: The physical science basis. Working Group I contribution to the Fifth Assessment Report of the Intergovernmental Panel on Climate Change. Cambridge University Press, Cambridge. https://doi.org/10.1017/CBO9781107415324

Islam MR (2021) Environment and disaster education in the secondary school curriculum in Bangladesh. SN Soc Sci 1:23

Islam ARMT, Shill BK, Salam R, Siddik MNA, Patwary MA (2021) Insight into farmers' agricultural adaptive strategy to climate change in northern Bangladesh. Environ Dev Sustain 23:2439-2464

Kabir M, Rahman MB, Smith W, Lusha M, Azim S, Milton A (2016) Knowledge and perception about climate change and human health: findings from a baseline survey among vulnerable communities in Bangladesh. BMC Public Health 16:1-10

Khan R, Kiefer D (2007) Educational production functions for rural Pakistan: a comparative institutional analysis. Educ Econ 15(3):327-342

Littrell MK, Tayne K, Okochi C, Leckey E, Gold AU, Lynds S (2020) Student perspectives on climate change through place-based filmmaking. Environ Educ Res 26(4):594-610

Lorenzoni I, Nicholson-Cole S, Whitmarsh L (2007) Barriers perceived to engaging with climate change among the UK public and their policy implications. Glob Environ Chang 17(3):445-459

Ludden D (2003) Investing in nature around Sylhet: an excursion into geographical history. Econ Pol Wkly 38(48):5080-5088

Manandhar S, Pratoomchai W, Ono K, Kazama S, Daisuke K (2014) Local people's perceptions of climate change and related hazards in mountainous areas of northern Thailand. Int $\mathrm{J}$ Disaster Risk Reduct 11:47-59

Marie M, Yirga F, Haile M, Tquabo F (2020) Farmers' choices and factors affecting adoption of climate change adaptation strategies: evidence from northwestern Ethiopia. Heliyon 6(4):e03867

Masud MM, Akhatr R, Nasrin S, Adamu IM (2017) Impact of sociodemographic factors on the mitigating actions for climate change: a path analysis with mediating effects of attitudinal variables. Environ Sci Pollut Res 24:26462-26477

McCright AM (2010) The effects of gender on climate change knowledge and concern in the American public. Popul Environ 32:66-87

Meilinda M, Rustaman NY, Tjasyono B (2017) The perceptions of pre-service science teachers and science teachers about climate change. Indonesian J Sci Educ 6(2):292-297

Morgado F, Bacelar-Nicolau P, Rendon-Von Osten J, Santos P, Bacelar-Nicolau L, Farooq H, Alves F, Soares AMVM, Azeiteiro UM (2017) Assessing University student perceptions and comprehension of climate change (Portugal, Mexico and Mozambique). Int J Clim Change Strateg Manag 9(3):316-336

Mugambiwa SS, Dzomonda O (2018) Climate change and vulnerability discourse by students at a South African university. J Disaster Risk Stud 10(1):476

Muralidharan K, Kremer M (2008) Public and private schools in rural India. In: Peterson P, Chakrabarti R (eds) School choice international. MIT Press, Cambridge

Nakayama M, Taafaki I, Uakeia T, Seru J, McKay Y, Lajar H (2019) Influence of religion, culture and education on perception of climate change, and its implications. J Disaster Res 14(9):1297-1302

Pandve HT, Raut A (2011) Assessment of awareness regarding climate change and its health hazards among the medical students. Indian J Occup Environ Med 15(1):42-45

Porter D, Weaver AJ, Raptis H (2012) Assessing students' learning about fundamental concepts of climate change under two different conditions. Environ Educ Res 18(5):665-686

Prokopy LS, Arbuckle JG, Barnes AP, Haden VR, Hogan A, Niles MT, Tyndall J (2015) Farmers and climate change: a cross-national comparison of beliefs and risk perceptions in high-income countries. Environ Manag 56:492-504

Punter P, Ochando-Pardo M, Garcia J (2011) Spanish secondary school students' notions on the causes and consequences of climate change. Int J Sci Educ 33(3):447-464

Rahman S (2003) Environmental impacts of modern agricultural technology diffusion in Bangladesh: analysis of farmers' perceptions and their determinants. J Environ Manag 68(2):183-191 
Rahman MR, Lateh H (2017) Climate change in Bangladesh: a spatio-temporal analysis and simulation of recent temperature and rainfall data using GIS and time series analysis model. Theoret Appl Climatol 128:27-41

Rahman SMA, Tasmin S, Uddin MK, Islam MT, Sujauddin M (2014) Climate change awareness among the high school students: Case study from a climate vulnerable country. Int J Built Environ Sustain $1: 18-26$

Reser JP, Swim JK (2011) Adapting to and coping with the threat and impacts of climate change. Am Psychol 66(4):277-289

Rimm-Kaufman SE, Storm MD, Sawyer BE, Pianta RC, LaParo K (2006) The teacher belief Q-sort: a measure of teachers' priorities and beliefs in relation to disciplinary practices, teaching practices, and beliefs about children. J Sch Psychol 44(2):141-165

Sarkar S, Padaria RN, Lal K, Bhatia A (2012) Farmers' perception and attitude toward climate change in coastal ecosystem of West Bengal. Indian Res J 12(2):10-16

Scannell L, Gifford R (2013) Personally relevant climate change: the role of place attachment and local versus global message framing in engagement. Environ Behav 45(1):60-85

Selby D, Kagawa F (2012) Disaster risk reduction in school curricula: case studies from thirty countries. UNESCO and UNICEF, Paris

Semenza JC, Hall DE, Wilson DJ, Bontempo BD, Sailor DJ, George LA (2008) Public perception of climate change voluntary mitigation and barriers to behavior change. Am J Prev Med 35(5):479-487

Shaffril HAM, Krauss SE, Samsuddin SF (2018) A systematic review on Asian farmers' adaptation practices towards climate change. Sci Total Environ 644(10):683-695

Shealy T, Klotz L, Godwin A, Hazari Z, Potvin G, Barclay N, Cribbs J (2019) High school experiences and climate change beliefs of first year college students in the United States. Environ Educ Res 25(6):925-935

Shepardson DP, Niyogi D, Roychoudhury A, Hirsch A (2012) Conceptualising climate change in the context of a climate system: Implications for climate and environmental education. Environ Educ Res 18(3):323-352

Shi J, Visschers VHM, Siegrist M, Arvai J (2016) Knowledge as a driver of public perceptions about climate change reassessed. Nat Clim Chang 6:759-762

Shukla G, Kumar A, Pala NA, Chakravarty S (2015) Farmers perception and awareness of climate change: a case study from Kanchandzonga Biosphere Reserve, India. Environ Dev Sustain 18(4):1167-1176

Stevenson K, Peterson M, Bradshaw A (2016) How climate change beliefs among US teachers do and do not translate to students. PLoS ONE. https://doi.org/10.1371/journal.pone.0161462

Stooksberry LM, Schussler DL, Bercaw LA (2009) Conceptualising dispositions: intellectual, cultural, and moral domains of teaching. Teach Teach 15(6):719-736

Suppramaniam S, Kularajasingam J, Sharmin N (2019) Factors influencing parents decision in selecting private schools in Chittagong city, Bangladesh. Int J Recent Technol Eng 7(5S):318-330

Tehrani IA, Mansor WFAW (2012) The influence of teacher autonomy in obtaining knowledge on 'Class Practice.' Procedia Soc Behav Sci 66:544-554

The Asia Foundation (2012) Climate change perception survey. Dhaka: The Asia Foundation. https:// asiafoundation.org/resources/pdfs/ClimateChangeperceptionsurvey.pdf. Accessed 27 July 2020

Ullah W, Nafees M, Khurshid M, Nihei T (2019) Assessing farmers' perspectives on climate change for effective farm-level adaptation measures in Khyber. Environ Monit Assess 191:547

Wolf J, Moser SC (2011) Individual understandings, perceptions, and engagement with climate change: Insights from in-depth studies across the world. Wiley Interdiscip Rev 2(4):547-569

Yamba S, Appiah DO, Siaw LP (2019) Smallholder farmers' perceptions and adaptive response to climate variability and climate change in southern rural Ghana. Cogent Soc Sci 5(1):1646626

Yu H, Wang B, Yue-Jun Z, Wang S, Yi-Ming W (2013) Public perception of climate change in China: results from the questionnaire survey. Nat Hazards 69:459-472 


\section{Authors and Affiliations}

Mohammed Thanvir Ahmed Chowdhury ${ }^{1} \cdot$ Khandaker Jafor Ahmed $^{2}$. Mufti Nadimul Quamar Ahmed ${ }^{1}$. Shah Md. Atiqul Haq ${ }^{3}$ (D)

1 Department of Applied Sociology and Social Work, North East University Bangladesh, Sylhet 3100, Bangladesh

2 Department of Geography, Environment and Population, The University of Adelaide, Adelaide, SA 5005, Australia

3 Department of Sociology, Shahjalal University of Science and Technology, Sylhet 3114, Bangladesh 